\title{
Minireview
}

\section{Production of Eucommia-rubber from Eucommia ulmoides Oliv. (Hardy Rubber Tree)}

\author{
Yoshihisa Nakazawa ${ }^{1,2, *}$, Takeshi Bamba², Tuyoshi Takeda², Hirotaka Uefuji, \\ Yoko Harada ${ }^{1}$, Xuehong $\mathrm{Li}^{1}$, Ren Chen ${ }^{1}$, Sumihiro Inoue ${ }^{1}$, Masafumi Tutumi ${ }^{1}$, \\ Toru Shimizu', Yin-Quan $\mathrm{Su}^{3}$, Koichiro Gyokusen ${ }^{4}$, Eiichiro Fukusaki², \\ Akio Kobayashi \\ ${ }^{1}$ Technical Research Institute, Hitachi Zosen Corporation, Osaka 551-0022, Japan; ${ }^{2}$ Department of Biotechnology, \\ Graduate School of Engineering, Osaka University, Suita, Osaka 565-0871, Japan; ${ }^{3}$ Forestry Faculty, Northwest Sci- \\ Tech University of Agriculture and Forestry, No. 3, Tai Cheng Road, Yang Ling, Shaanxi 7121000, China; ${ }^{4}$ Department \\ of Forest and Forest Products Sciences, Faculty of Agriculture, Kyushu University, Fukuoka 812-8581, Japan \\ *E-mail: nakazawa@bio.eng.osaka-u.ac.jp Tel \& Fax: +81-6-6879-4146
}

(Received January 20, 2009; accepted February 2, 2009 (Edited by D. Shibata)

\begin{abstract}
Eucommia ulmoides Oliver is a deciduous tree distributed in China, and is the only species in its genus, and the only genus in its family. It grows in temperate zones, and produces long-chain trans-polyisoprene throughout the entire plant. This trans-polyisoprene (TPI) derived from Eucommia is called Eucommia rubber (EU-rubber), and is a hydrocarbon with a carbon molecular weight of a few hundred thousand. EU-rubber is a hard rubber with thermoplasticity, and has properties similar to plastic. In terms of practical use, these plant-derived polymers are attracting attention as an industrial raw material to substitute for petroleum, and demand is expected to grow in the future. Hydrocarbon is also a fuel which has energy with the same value as petroleum.
\end{abstract}

Key words: Eucommia, trans-polyisoprene, EU-rubber, Rubber producing plant.

Polyisoprene is an isoprenoid compound produced by plants which shows promise as a raw material (natural rubber) to replace synthetic rubber made from petroleum. Plant polyisoprene is classified into two types, cis-polyisoprene (CPI) and trans-polyisoprene (TPI), depending on the polymerization style of the isoprene unit. Taraxacum koksaghyz and many other plants are known to produce long-chain CPI, and the CPI produced by Hevea brasiliensis is widely used in commercial applications (Archer et al. 1973). On the other hand, a small number of plants are known to produce long-chain TPI, including Eucommia ulmoides, Palaquium gutta, and Mimusops balata. TPI derived from $P$. gutta is used commercially in some camera grips and as a root canal filler (Gutta-percha). At present, TPI is chemically synthesized, and is primarily used in applications such as golf ball coverings, casts, sports protectors, and mold material for wigs. TPI is a thermoplastic elastomer with a low melting point and high elasticity, and is also useful as an insulator.

Eucommia (Eucommia ulmoides Oliver) is a woody plant native to China which produces a hard, fibrous long-chain TPI (Hendricks et al. 1946; Shiu-ying 1978).
All parts of Eucommia contain TPI. For these reasons, Eucommia shows great promise as a next-generation biomass resource. The bark of Eucommia has been used since ancient times as a nutritional supplement and herbal remedy for high blood pressure. Eucommia contains iridoid glucoside (geniposidic-acid), a type of isoprenoid, and this is thought to have a blood pressure lowering effect (Deyama et al. 2001). The leaves are also used as the basic ingredient of Tochu tea (Du zhong tea), and the plant is cultivated in Japan. Eucommia is useful both as an industrial and food material, and is an industrial tree suitable for commercialization. Whereas other TPI-producing plants ( $P$. gutta, M. balata) only grow in the tropics, Eucommia can grow even in temperate and cold regions. However, in order for Eucommia to become a practical source of TPI, it must be modified to further increase TPI production, and enable stable supply as an industrial raw material. Possible approaches for doing that include: cultivar improvement, selection of elite trees, examination of cultivation conditions, and development of recombinants with modifications to the gene cluster relating to TPI biosynthesis. Here we review 
Here we review the research of Eucommia as a plant with the potential to produce industrial raw materials, and the production of EU-rubber.

\section{Features of Eucommia as a rubber producing plant}

Eucommia is native to central southern China. It is a tall deciduous tree, naturally distributed in an elevation range of $600-2500 \mathrm{~m}$, and grows to a height of about $20 \mathrm{~m}$. Taxonomically, it is regarded as an independent species in the Cronquist system for the classification of flowering plants, where it is the only species in the only genus of the family Eucommiaceae. In the Angiosperm Phylogeny Group (APG) classification system it is classified under the family Eucommiaceae of the order Garryales. The plant is dioecious, with $2 \mathrm{n}=34$ chromosome numbers. It is wind pollinated, and the filaments, anthers and ovaries differentiate at the same time as new growth from the axillary buds of offshoots which are at least 3 years old (Figure 1). After fertilization, the ovary sites grow and become seeds (Figure 2). These seeds have a mericarp morphology similar to Ulmaceae, and are shaped as samaras for dispersal by wind.
The natural and cultivated distributions of Eucommia are shown in Figure 3. The northern limit of the natural distribution was the Qinling Mountains in southern Shaanxi Province, where there is a boundary between China's floral regions, and the tree was distributed as far as Yunnan in the south, and close to Jiangxi in the east. However, its numbers have drastically decreased due to overexploitation in the 1970s. Today it survives locally only in mountainous areas where people cannot settle, and the wild species has been designated as a Chinese endangered species with a high risk of extinction. However, there has been reforestation since the late 1980s, with cultivation sites established in many areas. The tree is also cultivated as a raw material for herbal medicine in regions such as northern China, Japan, South Korea, Taiwan, and Northern Vietnam.

Eucommia is a primitive angiosperm, and fossils reportedly show that a few species were distributed worldwide up to the late Pliocene (approx. 6 million years ago), (Victor B.C. and David L.D. 1997). The cause of the sharp decrease in species is thought to be the four ice ages which arrived later, and Eucommia is a plant version of a "living fossil."

Eucommia has been used in China since the pre-

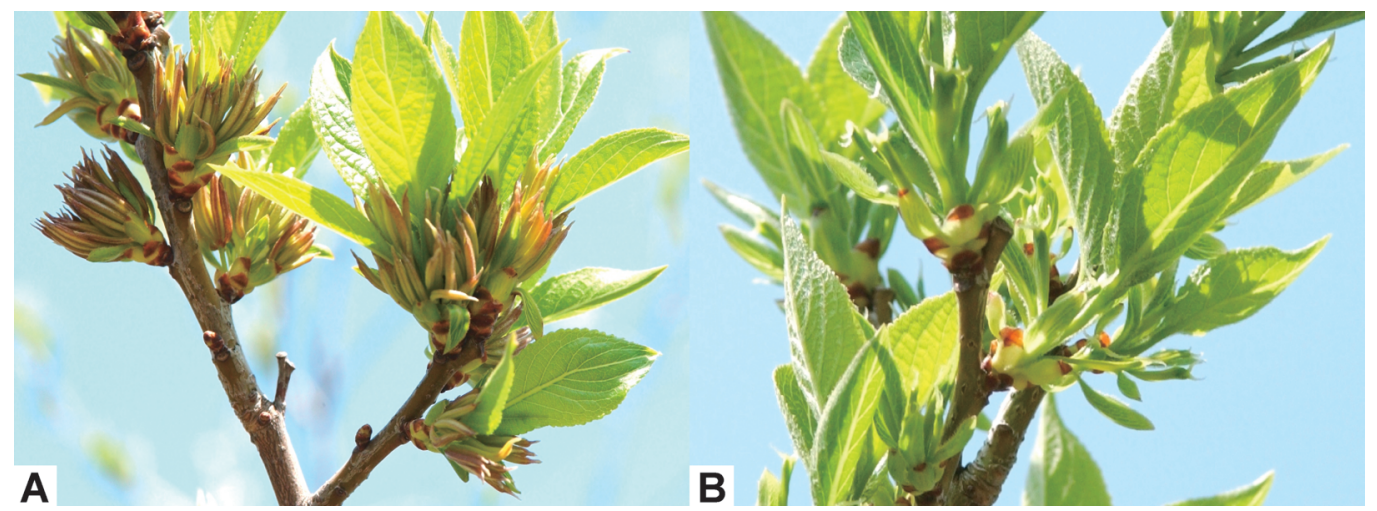

Figuer 1. Flower of Eucommia. It has no flower organs because it is wind pollinated, and the filaments, anthers and ovaries differentiate at the same time as new growth from the axillary buds of offshoots which are at least 3 years old. A: Male flower, B: Female flower. The first week of April, spring Osaka in japan.
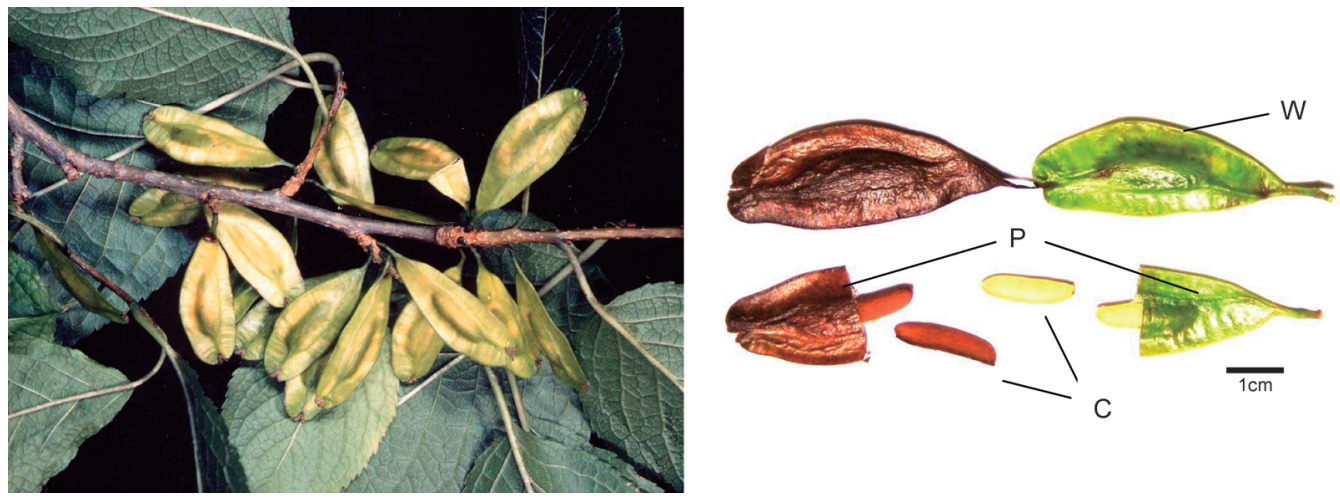

Figure 2. Mature seed of Eucommia. The Eucommia flower of after fertilization, the ovary sites grow and become seeds. These seeds have a mericarp morphology similar to Ulmaceae, and are shaped as samaras for dispersal by wind. P: pericarp, C: cotyledon, W: wing. 


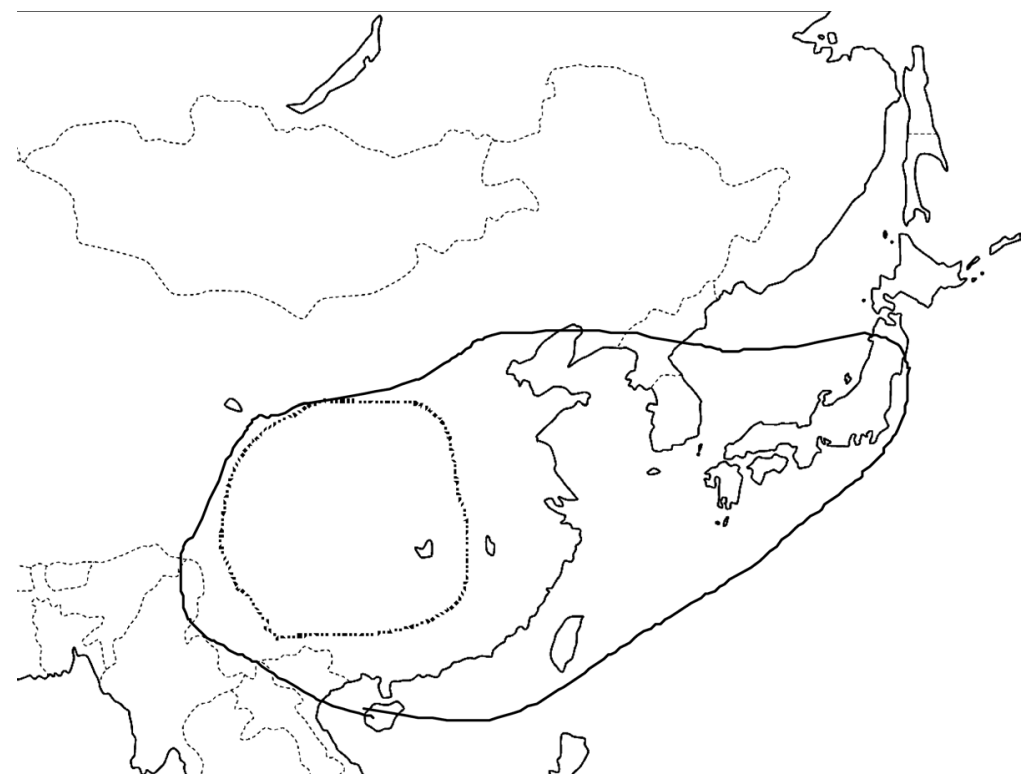

Figure 3. Natural and cultivated distributions of Eucommia. The solid line cultivated as a raw material for herbal medicine in regions such as northern China, Japan, South Korea, Taiwan, and Northern Vietnam. And Dotted line natural distribution was the Qinling Mountains in southern Shaanxi Province, where there is a boundary between China's floral regions, and the tree was distributed as far as Yunnan in the south, and close to Jiangxi in the east.

Christian era, and was listed as "SHANG PIN" in the ancient Chinese pharmacopoeia Shennong Bencao Jing (The Divine Farmer's Herb-Root Classic). It was first botanically recognized in 1887 , when it was collected by the English botanist Daniel Oliver from the Yangtze basin. In 1890 it was planted in the Royal Botanic Gardens, Kew. Repropagated individuals were planted in 1930, and still survive. In the early 1900s, seeds were distributed from Kew Gardens, and specimens can now be seen in the major botanical gardens of Europe and North America. The plant was introduced to Japan by the Japanese army in 1914, for the purpose of rubber harvesting, and planted in the foreign tree garden of the Forestry Agency. Trees planted at that time survive today in the Oneyama Experimental Forest (currently a Gunma Prefecture Forest Park), and have grown to more than $20 \mathrm{~m}$ in height.

The distinguishing feature of Eucommia is TPI, which is found in all parts of the plant. The botanical name "Eucommia" indicates the tree's morphological characteristics in Latin, with "Eu" meaning "good" and "commia" meaning "gum." Weiss F. E. (Weiss 1899) called "A Gutta-percha Plant" in 1899, and The Kew Bull. (Anonymous 1901) called EU-rubber "Guttapercha from a Chinese tree" in 1901, and until it was reported to be long-chain TPI (Hendricks et al. 1947), it was thought to be the same as the Gutta-percha produced by $P$. gutta, which was used in golf balls at that time. However, the rubber produced by $P$. gutta is a milky liquid, while the rubber produced by Eucommia is solid. Therefore, Bamba et al. (Bamba et al. 2003) distinguished it as "Eucommia-Rubber" (EU-rubber).
The authors define EU-rubber as long-chain TPI produced by Eucommia, and treat it as a different substance than the Gutta-percha of $P$. gutta. The term "EU-gum" is also used (Yang et al. 1995), but generally this refers to an industrial material comprised of low molecular weight TPI $\left(\overline{M_{n}}=6.0 \times 10^{3}\right)$ processed from Eucommia leaves and containing high levels of foreign matter.

\section{Accumulation of EU-rubber}

Research on Eucommia-derived TPI primarily concerns its molecular structure, and its distribution in the tissues of each organ. The oldest literature reference on Eucommia (before EU-rubber was confirmed to have the TPI structure) reported that the tree produces and accumulates a hard fibrous rubber in special secretory cells (Weiss 1892). Weiss noted that the rubbercontaining cells of Eucommia extend as though sewing the intercellular spaces of the cortex, pith and phloem; exhibit an elongate morphology with no branching structure; and have a single nucleus and thick cell wall. Research has also been done on the generation and growth of the rubber-containing cells of Eucommia (Weiss 1892; Tian 1990). Weiss reported that rubbercontaining cells are produced in both primary and secondary growth processes. Rubber-containing cells produced in the primary growth process are found in the cortex and pith, and rubber-containing cells produced in the secondary growth process are found in secondary phloem. Both Weiss and Tian et al. reported that rubbercontaining cells found in the cortex are produced by 
division of parenchyma cells in the cortex; that those cells grow intrusively, pushing the gap between cells wider; and that granular rubber accumulates inside those cells. Whereas Weiss speculated that eventually the rubber granules fuse, and become uniform fibrous rubber, Tian believed that the granular rubber retains that state without fusing. Their opinions differ on that point, but their views on the generation and growth of rubbercontaining cells are almost the same. As indicated, these researchers made detailed observations of the mechanisms underlying production and accumulation of EU-rubber. However, the remaining images of the sketches and other illustrations from this work are poor in quality, and it was not possible to obtain a stereoscopic image clearly indicating the localization of rubber. This has been a problem because previous findings rely on the observations and conjectures of Weiss and Tian et al.

Low observation precision was a problem for previous methods of observing rubber components in vivo (observation by optical microscope and FT-IR microanalysis), and to improve that precision, the authors have studied a technique of using a spectral confocal laser scanning microscopy (SCLSM) to specifically visualize EU-rubber and analyze it with higher precision (unpublished). After preparing a fresh frozen section of phloem tissue from the stem of Eucommia, the tissue was dyed with Nile red (a lipid-soluble pigment whose maximum fluorescence wavelength varies depending on differences in the polarity of the surrounding environment). The tissue was then observed with SCLSM. The fluorescence signal specific to EU-rubber was extracted using the linear unmixing feature of SCLSM. The results confirmed non-destructively that fibrous EU-rubber is distributed in the cortex and phloem (unpublished data).

The molecular structure of natural rubber derived from the leaves and bark of Eucommia has been analyzed using ${ }^{1} \mathrm{H}-\mathrm{NMR}$ and ${ }^{13} \mathrm{C}-\mathrm{NMR}$ (Tangpakdee et al. 1997). This analysis showed that the natural rubber of Eucommia is comprised of dimethylallyl groups, 60-3000 trans isoprene units, and terminal fatty acid ester groups or diphosphoric groups. In addition, Bamba et al. have conducted a molecular weight distribution analysis using a size exclusion chromatograph (SEC), and a structural analysis of Eucommia polyprenol using a supercritical fluid chromatograph. For details on the analysis techniques, please refer to the report by Bamba et al. Takeno et al. have developed high throughput screening using PyGC/MS, and analysis techniques which work with down size.

The authors conducted a comparative examination of the molecular weight distribution and content of each organ: cortex, leaves, roots and pericarp. For each organ, Figure 4 (unpublished data) shows the molecular weight distribution and Table 1 (unpublished data) shows the content. The pericarp was the organ with the largest polymers and the highest content. The levels then decreased in the order: bark, roots, leaves. However,
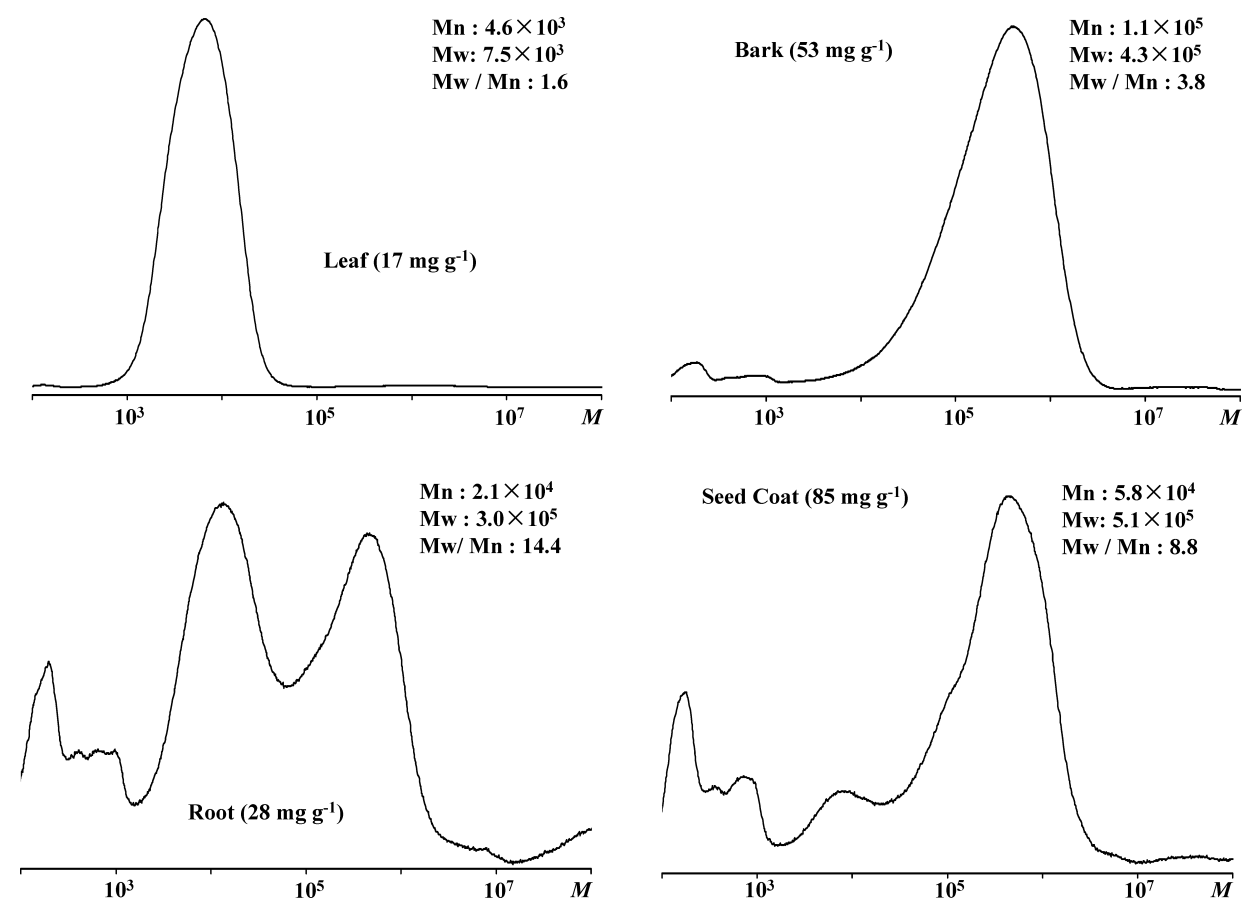

Figure 4 Size exclusion chromatography of EU-Rubber fractions from Eucommia organs. SEC analysis of EU-rubber and content derived from Eucommia organs: cortex, leaves, roots and pericarp. Conditions: System: Hitachi 7000 series, Sic 480 II (SYSTEM INSTRUMENTS), Column: PLgel MIXED-B $(5 \mathrm{~m}, \mathrm{f} 7.5 \times 300 \mathrm{~mm}) \times 2$ (Polymer Laboratories), Eluent: THF, Flow rate: $0.8 \mathrm{ml} / \mathrm{min}$, Detection : RI, Column Temp.: $40^{\circ} \mathrm{C}$, Calibration : polyisoprene. 
Table 1. EU-rubber content of Eucommia organs.

\begin{tabular}{lccccc}
\hline \multicolumn{1}{c}{ Organs } & Leaves & Barks & Roots & Seeds & Pericarps \\
\hline Content (\%) & $2-6$ & $8-12$ & $5-10$ & $13-20$ & $25-32$ \\
Average content (\%) & 3 & 10 & 7 & 18 & 28 \\
\hline
\end{tabular}

Soxhlet extraction. This data unpublished

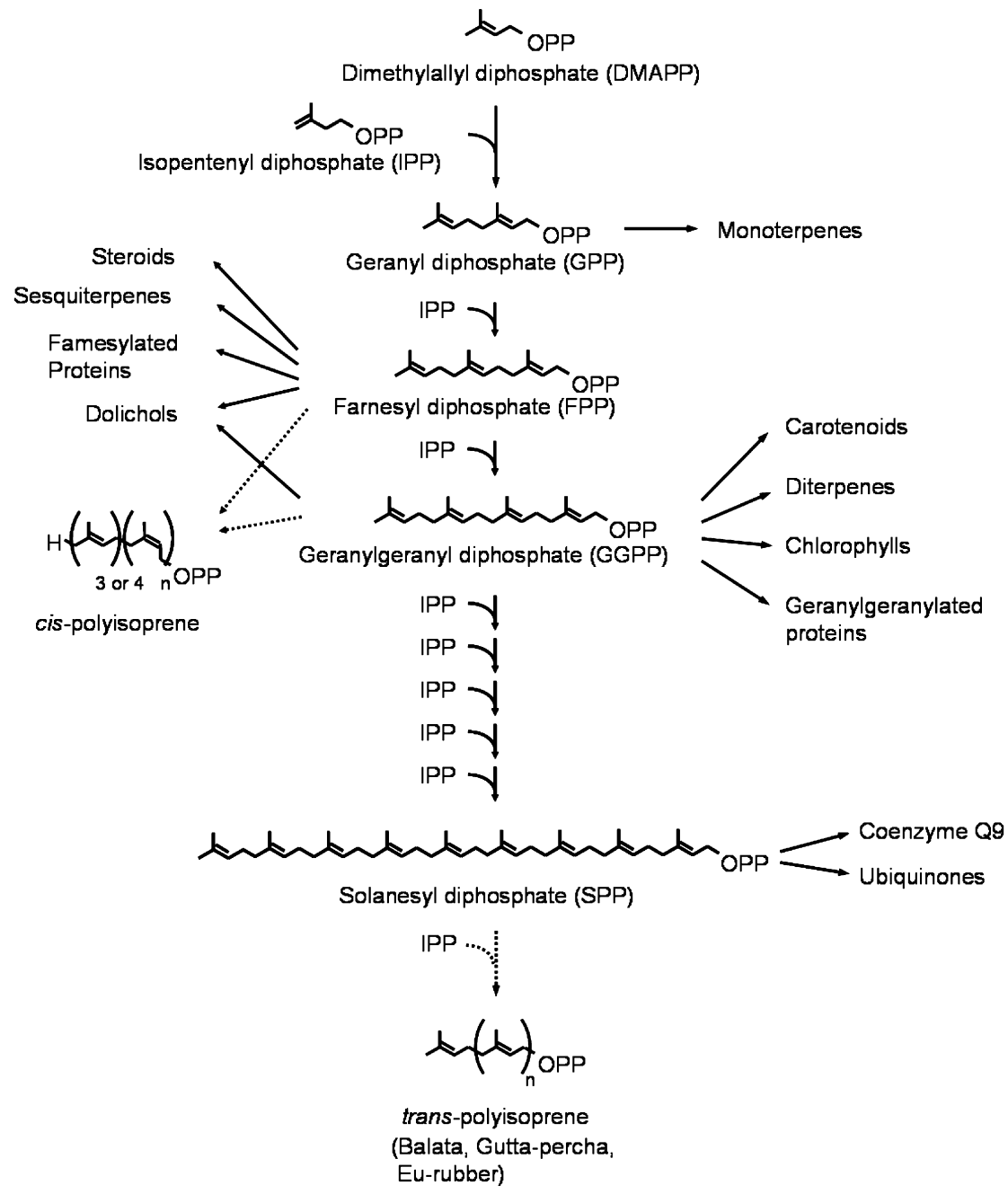

Figure 5. Biosynthesis of trans-polyisoprene.

roots and leaves exhibited a bimodal molecular weight distribution.

These results suggest that the pericarp is the most suitable tissue for use as an industrial raw material (unpublished data).

\section{TIP biosynthesis of Eucommia}

Due to their molecular structure, it is thought that isoprenoid compounds are synthesized through repetition of a reaction where isopentenyl diphosphate, an isoprene unit with a carbon number of 5 , condenses in head-to-tail fashion onto allyl diphosphate (Figure 5). The enzymes which catalyze this sort of prenyl chain length extension reaction are generically known as "prenyl transferase."
Farnesyl diphosphate (FPP, $\mathrm{C}_{15}$ ) and geranylgeranyl pyrophosphate (a short-chain isoprenoid compound, GGPP, $\mathrm{C}_{20}$ ) are short-chain isoprenoids, and the gene sequences of the FPP synthase and GGPP synthase which catalyze their synthesis reactions have been isolated for many organisms including plants, and a functional analysis has been done (Koyama et al. 1999). In plants, the genes for solanesyl diphosphate ( $\mathrm{SPP}, \mathrm{C}_{45}$ ) synthase have been isolated for Arabidopsis thaliana and Hevea brasiliensis (Jun et al. 2004; Phatthiya et al. 2007), but thus far, genes have not been isolated for prenyl transferase, which is involved in the synthesis of longer chains. Nothing at all has been reported on enzymes directly related to the biosynthesis of longchain TPI produced by plants such as E. ulmoides, $P$. 
gutta, and M. barata, but prenyl transferase is believed to be involved in its biosynthesis.

\section{Eucommia breeding and arboriculture}

Genetic resources of Eucommia in China are somewhat limited. Surviving examples of the wild species with a chest-height diameter exceeding $1 \mathrm{~m}$ are rare because most trees were logged in the 1970s and 1980s. Trees produced from sprouts of these individuals are frequently found in mountain villages. In the period from 1985 to 1990, Zhang et al. (Zhang et al. 2002) selected an outstanding line of 110 trees with tree ages of at least 15 years, based on phenotype characteristics such as tree form, tree bark and chest-height diameter, from Eucommia breeding forests and natural forests on the Chinese mainland. Starting in 1990, the authors selected
40 clones using root sprouts, began cultivation tests starting with 2 year trees, and selected 24 individuals as elite trees. The authors used SEC to measure yearly changes in molecular weight distribution and content of EU-rubber for these 24 individuals (unpublished data). The results showed that while the average EU-rubber content of leaves is $3 \%$, the three elite trees eventually selected by the authors had a high EU-rubber content exceeding $6 \%$. Due to these results, it was determined that there is seasonal variation in EU-rubber content, and that EU-rubber increases until growth stops. It was also determined that there is little seasonal variation in molecular weight distribution (Figure 6). For this reason, the appropriate time for harvesting is thought to be after growth has stopped.

Arboriculture in China varies depending on the how Eucommia is used. In cultivation to harvest the bark and

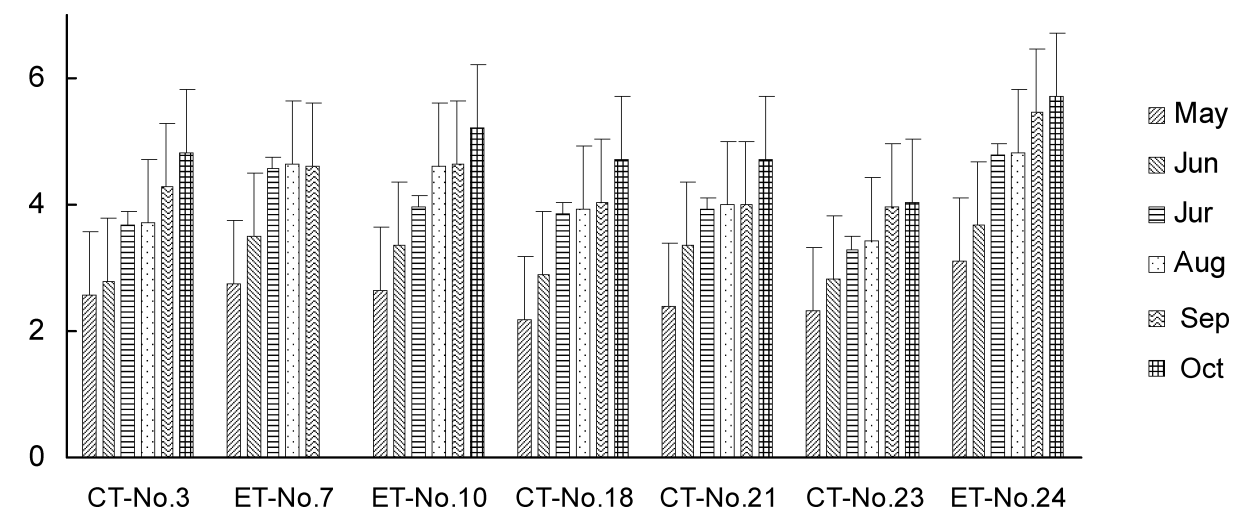

Figure 6. Growing type of Eucommia elite trees. It was determined that there is seasonal variation in EU-rubber content, and that EU-rubber ncreases until growth stops. It was also determined that there is little seasonal variation in molecular weight distribution. CT: Control Type (No. 3, 18, 23), ET: Elite tree type (No. 7, 10, 24). This data unpublished.

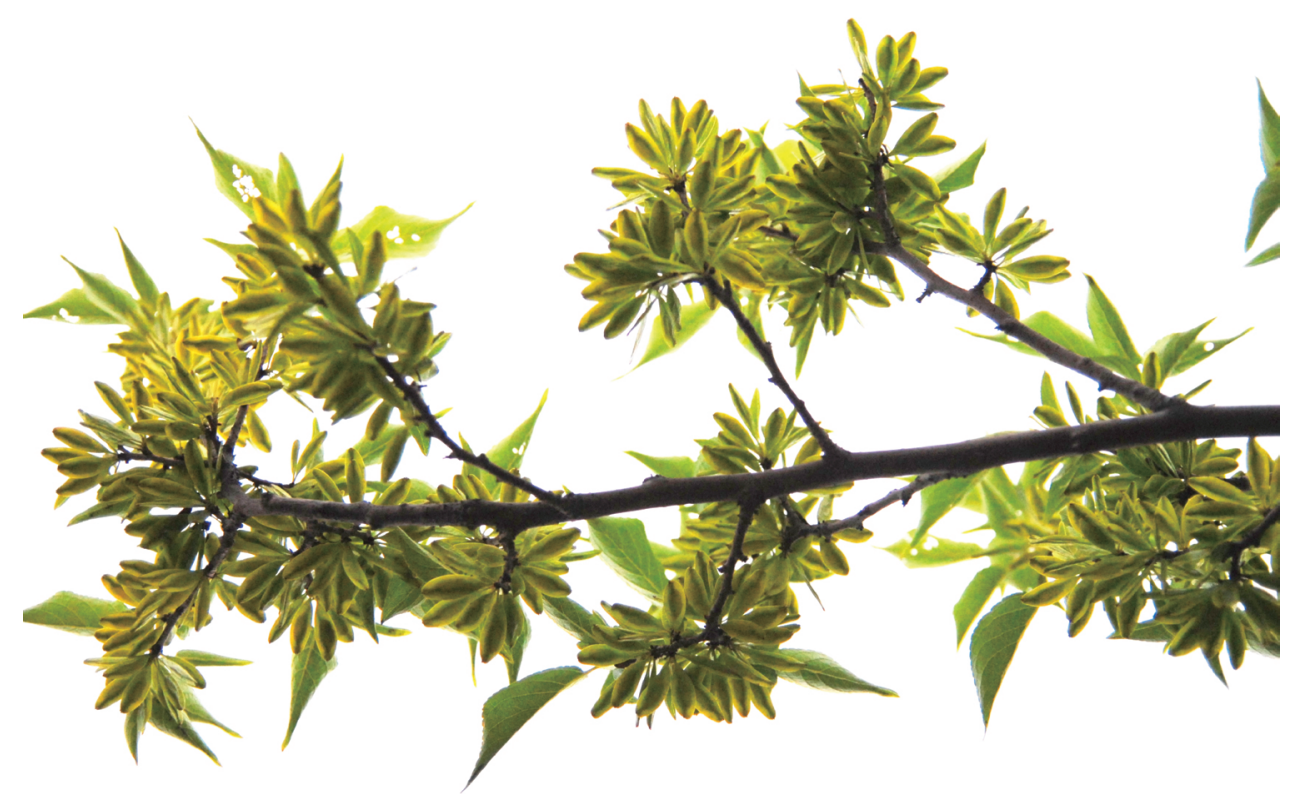

Figure 7. Eucommia arboriculture of seed production type. This technique makes it possible to address the problem of male/female occurrence and control seed productivity, and thereby enables large-scale production of seeds. Oil can also be produced from the seeds at the same time. 


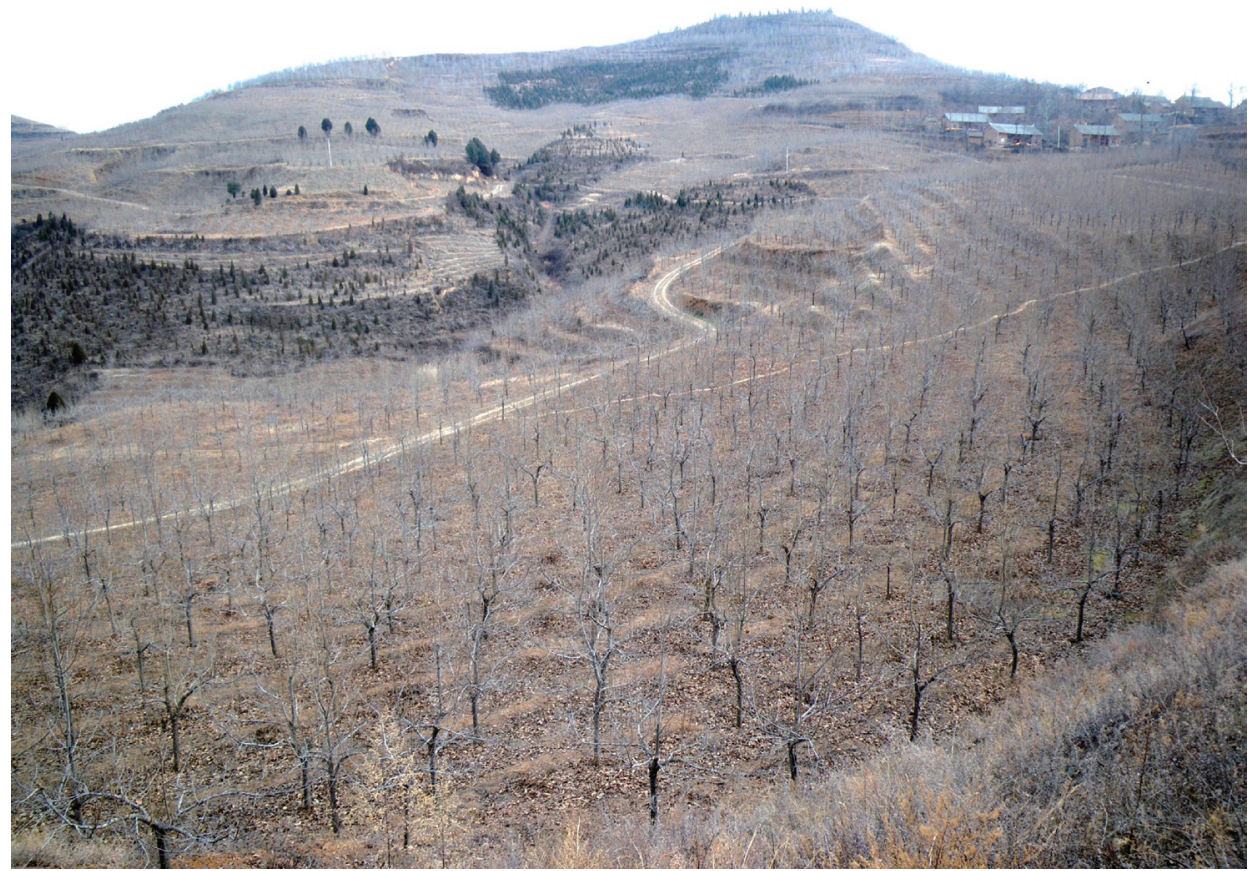

Figure 8. Cultivation project of Eucommia planting over 2 million trees. "Tiandi ecology science and technology Co., Ltd., Lingbao Henan Province in China". This technique may be an effective means of solving environmental issues and achieving the key policy of "abandoning cultivation and restoring forest" in western China, as encouraged by the Chinese government.

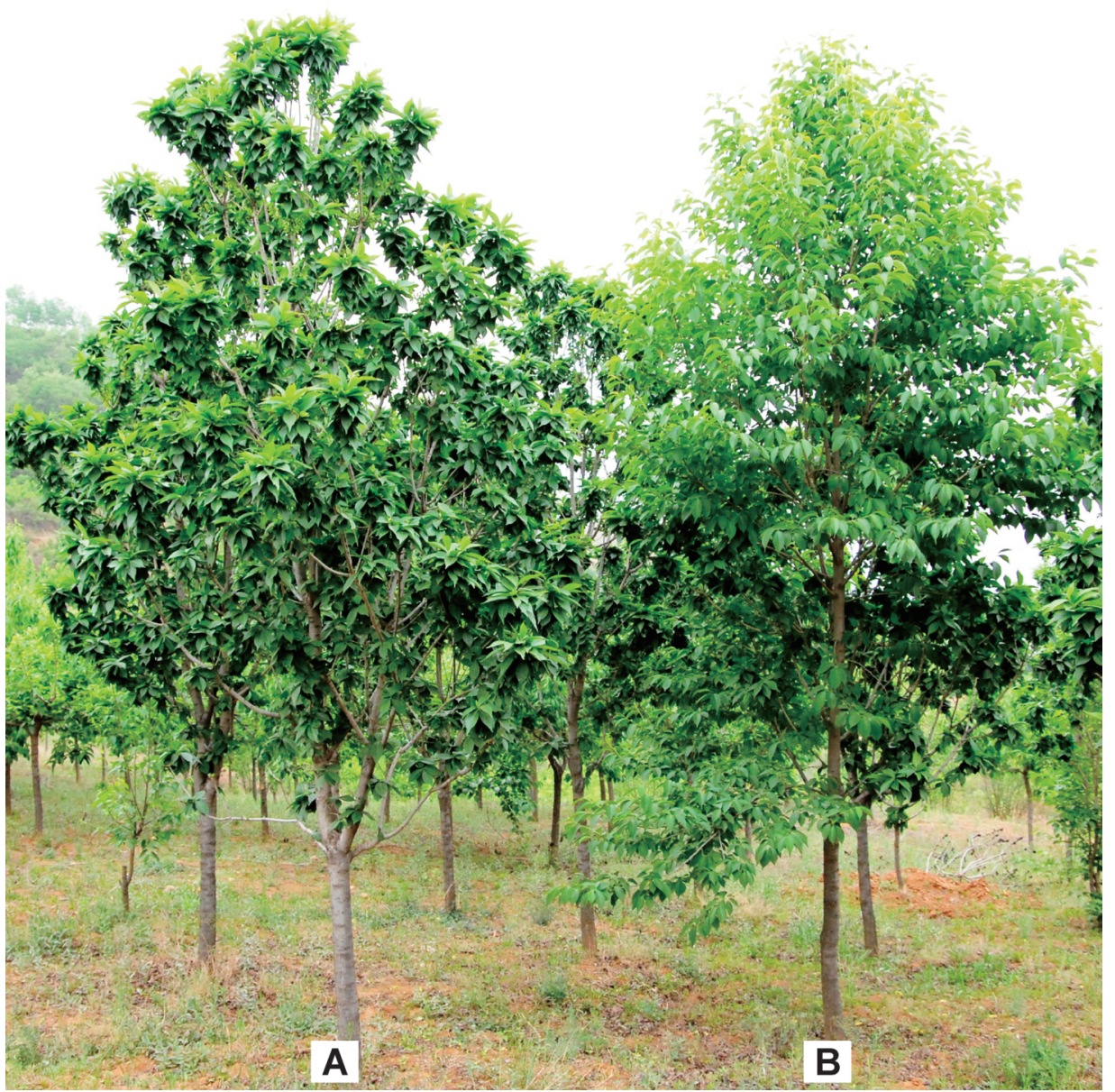

Figure 9. Eucommia arboriculture of horticulture applications. A: Horticulture type, B: Standard type. 
leaves, seen primarily in Sichuan Province, seedpropagated trees are closely planted with a spacing of $1-2 \mathrm{~m}$. Cultivation is done in an open style, without artificial pruning etc., and trunk density is high. When the trees reach about 10 years old, the bark is stripped, dried and marketed as a material for herbal medicine. After stripping, there is a waiting period for bark to regenerate, and after a few years of recuperation, the bark is stripped again. As a result, growth of biomass is extremely poor.

In order to produce leaves, the authors developed a technique where sprout branches are created by heavy pruning, and leaf growth is increased by a multiple of a few times due to the appearance of revived leaves (unpublished data). The leaves produced in this way have high nutritional value. Efforts are being made to use them as animal feed and, at the same time, to produce biomass using current year branches.

Tiandi ecology science and technology Co., Ltd. (Lingbao, Henan Province in China) have developed a cultivation method to produce seeds. They have selectively bred a line with prolific seed production (Figure 7), and successfully cultivated a line with prolific seed production through graft propagation using bud grafts. This technique makes it possible to address the problem of male/female occurrence and control seed productivity, and thereby enables large-scale production of seeds. Oil can also be produced from the seeds at the same time. A cultivation project of planting over 2 million trees using this technique has already been implemented through public-private collaboration (Figure 8). This technique may be an effective means of solving environmental issues and achieving the key policy of "abandoning cultivation and restoring forest" in western China, as encouraged by the Chinese government. Tiandi ecology science and technology Co., Ltd. have also selected lines suitable for horticulture, and are developing arboricultural applications such as cultivating roadside trees (Figure 9). In fact, 34 trees were roadside tree planted in Cleveland, Ohaio US, in 1952 (Barker A. P. 1984) and Eucommia planted through seed propagation are being used as shade trees on part of the West 4th. Ring Road inside Beijing.

\section{Conclusion}

At the beginning of the 20th century, studies were done on production of EU-rubber from Eucommia, but there were no specific methods for tree cultivation or extraction of EU-rubber, and progress remained stagnant for close to 100 years. In the last few years, however, new cultivation techniques have been established, and a practical production system for EU-rubber is coming into being. Eucommia is an easy to cultivate tree which grows in temperate regions, has high cold hardiness and drought resistance, and robust sprouting capability in response to pruning. By exploiting these characteristics, it can be mass cultivated in any temperate region. It can be cultivated on unused lands to achieve environmental protection goals such as greenification and water management, and to help build a low-carbon society through the hydrocarbon accumulation of EU-rubber etc.

\section{Acknowledgements}

This work was supported by the New Energy and Industrial Technology Development Organization (NEDO) of Project by Fundamental technologies for controlling the Material Production Process of Plants. We thank Professor Atsuhiko Shinmyo (Nara Institute of Science and Technology), Dr. Daisuke Shibata (Kazusa DNA Research Institute), Director Masafumi Ishii (Research Association for Biotechnology) and Dr. Hideyuki Suzuki (Kazusa DNA Research Institute) for critical reading of the manuscript.

\section{Reference}

Archer B L, Audley B G 1973 Rubber gutta percha and chicle. Phytochem 2: 310-343

Anonymous 1901 Gutta parcha from a Chinese tree. Kew Bull: 89-94

Bamba T, Fukusaki E, Nakazawa Y, Kobayashi A 2002 In-situ chemical analyses of trans-polyisoprene by histochemical staining and Fourier transform infrared microspectroscopy in a rubber-producing plant, Eucommia ulmoides Oliver. Planta 215: 934-939

Bamba T, Fukusaki E, Nakazawa Y, Kobayashi A 2004 Rapid and high-resolution analysis separation of geometric polyprenol geometric homologues by the connected octadecylsilylated monolithic silica columns in high-performance liquid chromatography. J Separation Sci 27: 293-296

Bamba T, Fukusaki E, Minakuchi H, Nakazawa Y, Kobayashi A 2005 Separation of polyprenol and dolichol by monolithic silica capillary column chromatography. J Lipid Re 46: 2295-2298

Bamba T, Shimonishi N, Matsubara A, Hirata K, Nakazawa Y, Kobayashi A, Fukusaki E 2008 High Throughput and Exhaustive Analysis of Diverse Lipids by Using Supercritical Fluid Chromatography-Mass Spectrometry for Metabolomics. J Biosci Bioeng 105: 460-469

Barker A P 1984 Eucommia ulmoides: A tree for urban areas. J Arboricul 10: 233-235

Deyama T, Nishibe S, Nakazawa Y 2001 Constituents and pharmacological effects of Eucommia and Siberian ginseng. Acta Pharma Sinica 22: 1057-1070

Hendricks S B, Wildman S G, Jones E J, 1946 Differentiation of rubber and gutta hydrocarbons in plant materials. Rubber Chem Technol 19: 501-509

Jun L, Saiki R, Tatsumi K, Nakagawa T, Kawamukai M 2004 Identification and subcellular localization of two solanesyl diphosphate synthases from Arabidopsis thaliana. Plant Cell Physiol 45: 1882-1888

Zhang K, Su Y, Zhang T 2002 Selection breeding of the Eucommia. Northwest Sci-Tech University of Agriculture and Forestry publisher (in Chinaese)

Koyama T 1999 Molecular analysis of prenyl chain elongating enzymes. Biosci Biotechnol Biochem 63: 1671-1676 
Phatthiya A, Takahashi S, Chareonthiphakorn N, Koyama T, Wititsuwannakul D, Wititsuwannakul R 2007 Cloning and expression of the gene encoding solanesyl diphosphate synthase from Hevea brasiliensis. Plant Sci 172: 824-831

Takeno S, Bamba T, Nakazawa Y, Fukusaki E, Okazawa A, Kobayashi A 2008 Quantification of trans-1,4-Polyisoprene in Eucommia ulmoides by Fourier Transform Infrared Spectroscopy and Pyrolysis-Gas Chromatography/Mass Spectrometry. J Biosci Bioeng 105: 355-359

Takeno S, Bamba T, Nakazawa Y, Fukusaki E, Okazawa A, Kobayashi A 2008 A High-Throughput and Solvent-free Method for Measurement of Natural Polyisoprene Content in Leaves by Fourier Transform Near Infrared Spectroscopy. J Biosci Bioeng 106: 537-540

Tangpakdee J, Tanaka Y, Shiba K, Kawahara S, Sakurai K, Suzuki Y 1997 Structure and biosynthesis of trans-polyisoprene from
Eucommia ulmoides. Phytochem 45: 75-80

Tian L-X, Lu M, Hu Z-H 1990 Studies on the initiation and development of gutta-containing cells of Eucommia ulmoides Oliv. Acta Botanica Sinica 32: 1-6

Tzen JTC, Huang AHC 1992 Surface structure and properties of plant seed oil bodies. J Cell Biol 117: 327-335

Weiss FE 1892 The Caoutchouc-Containing Cells of Eucommia ulmoides Oliver. Botany 3: 243

Weiss FE 1899 A Gutta-percha Plant. Nature 1566 61: 7

Yan R-F 1999 The Characteristics of the chain structure of Eucommia ulmoides Gum and Its Material Engineering. Proceeding of the first international symposium on Eucomma ulmoides. "China Forestry Publishing House publisher": 102110

Victor BC, David LD 1997 The fossil record of Eucommia (Eucommiaceae) in North America. J Bota 84: 978-814 